\title{
SISTEMA DE INFORMAÇÃO SOBRE NASCIDOS VIVOS NA CIDADE DO RIO DE JANEIRO 1993/1996
}

\author{
Rosanna lozzi da Silva', Mariza M. Theme Filha ${ }^{2}$, Cláudio Pompeiano Noronha ${ }^{3}$
}

Este trabalho enfoca o perfil dos nascidos vivos de mães residentes na cidade do Rio de Janeiro, no período de 1993 a 1996. Nele se descrevem as variáveis que compõem o formulário da declaração de nascido vivo (DN), fonte dos dados trabalhados pelo Sistema de Informação sobre Nascidos Vivos (SINASC). As características dos nascimentos na cidade foram avaliadas segundo condiçðes de gestação, características do parto, das mães e dos recém-nascidos. Também foi avaliada a qualidade do preenchimento dos formulários.

\section{Introdução}

Em 1990, o Ministério da Saúde implantava o Sistema de Informação sobre Nascidos Vivos (SINASC). A necessidade de criação desse sistema justificava-se pela precariedade das informações sobre nascimentos. Até então, essas informaçōes eram obtidas através dos registros civis realizados nos cartórios que periodicamente enviavam mapas de apuração desses dados à Fundação Instituto Brasileiro de Geografia e Estatística (FIBGE) que os analisava e divulgava. Entretanto, essa fonte de dados contém problemas de sub-registro e de qualidade/ fidedignidade das informações. Para comprovar tais imprecisóes foram realizados diversos trabalhos sobre o sub-registro legal dos nascimentos ${ }^{1}$.
Assim como as informações sobre mortalidade, as estatísticas sobre os nascimentos compóem o campo de trabalho das estatísticas vitais. Em relação à mortalidade, $o$ Ministério da Saúde já havia criado um sistema de informaçōes em 1975, o Sistema de Informação de Mortalidade (SIM), padronizando um tipo de formulário único - a declaração de óbito - para registro dos dados.

A criação do SINASC oferece uma resposta aos técnicos das mais diversas áreas, que se deparavam constantemente com a difícil tarefa de planejar, tendo como base estimativas. A caracterização de alguns aspectos sobre as condições de gestação, nascimento e características maternas passa a ser possível com a definição de um instrumento de coleta individual dos dados - a declaração de nascido

\footnotetext{
1 Médica Epidemiologista, Subgerência de Dados Virais, Gerência de Informação Epidemióógica, Coondenação de Programas de Epidemiologia, Superintendência de Saúde Coletiva, Secretaria Municipal de Saúde do Rio de Janeiro. (GIE/COE/SSC/ SMS-RJ)

${ }_{3}^{2}$ Médica Epidemiologista, Subgerente de Epidemiologia Aplicada aos serviços de Saúde, GIE/COE/SSC/SMS-RJ

3 Médico Epidemiologista, Gerente de Informaçáo Epidemiológica (GIE), COE/SSC/SMS-RJ.

Endereço para correspondência: Rua Afonso Cavalcanti , 455, $8^{\circ}$ andar, sala 828, CEP 20211-110, Cidade Nova, Rio de Janeiro -RJ. Tel.: (021) 5032239; 5032247; 5032268; FAX: (021) 273-7242 - e-mail: cnoronha@pcrj.rj.gov.br
} 
vivo (DN). À semelhança da declaração de óbito, a DN passa a ser um formulário de emissão obrigatória para que possa ser feito o registro civil do nascimento, seguindo a determinaçáo estabelecida no Estatuto da Criança e do Adolescente - Lei no 8069 de 13/ 07/90, Ministério da Saúde, 1990.

A implantação do SINASC em nível nacional vem ocorrendo gradativamente e a cargo das secretarias estaduais de saúde. Alguns ajustes operacionais diferenciaram a capacidade de implantação do SINASC nos diversos municípios brasileiros ${ }^{2}$.

No município do Rio de Janeiro, o Sistema de Informações sobre Nascidos Vivos foi implantado em 1992, mas é em 1993 que alcança a cobertura mais próxima da totalidade dos eventos de nascimentos da cidade. Dessa forma, a partir de 1993 o SINASC passa realmente a fazer parte da rotina de todos os serviços de saúde do município.

$\mathrm{Na}$ Secretaria Municipal de Saúde do Rio de Janeiro (SMS-RJ), cabe à Subgerência de Dados Vitais, da Gerência de Informação Epidemiológica, da Coordenação de Programas de Epidemiologia, a responsabilidade pela administração do sistema. Esse gerenciamento compreende desde o controle da distribuição dos formulários de $\mathrm{DN}$, para uso pelos estabelecimentos, até a análise e divulgação dos dados.

Um aspecto essencial do trabalho com o SINASC é a divulgação das informações por ele produzidas. Essa deve ser uma preocupação e um objetivo de todos os sistemas de informaçóes. A partir de 1995, a SMS-RJ passa a criar canais de divulgação dessas informaçōes, através de relatórios de trabalho, sobre o perfil dos nascidos vivos e mäes residentes na cidade, sobre o perfil dos principais estabelecimentos de saúde e sobre a avaliação da qualidade de preenchimento da DN.

A divulgação das informações produzidas pelo SINASC tem alcançado nāo só as unidades de saúde do setor público mas também as privadas. Tem-se procurado chamar a atenção dos profissionais de saúde para a importância do registro das informaçóes básicas para o conhecimento das condiçóes de saúde da população, para dessa forma poder intervir nos principais problemas.

O simples conhecimento do número de nascidos vivos a cada ano possibilita o cálculo da taxa de mortalidade infantil e da taxa de mortalidade materna, dois indicadores tradicionalmente utilizados para o monitoramento das condiçóes de vida da população. Até a implantação do SINASC, o cálculo dessas taxas era realizado com base nas estimativas populacionais, o que gerava algumas imprecisóes. A partir do SINASC, os dados disponíveis estão mais próximos da realidade.

Em relaçáo à qualidade dos dados gerados pelo SINASC, é importante ressaltar que o preenchimento da DN é executado por profissionais de diferentes áreas e que, ao contrário da declaração de óbito, preenchida exclusivamente por médicos e com baixa qualidade das informações fornecidas, a DN é um formulário bem utilizado. Ao longo desses quatro anos de funcionamento do sistema observaram-se melhorias identificadas a partir do acompanhamento da freqüência do nãopreenchimento dos campos que compóem a DN.

Após completados o processamento dos dados e as revisōes pertinentes do ano de 1996, serão apresentados os resultados desses quatro anos de trabalho, compreendendo o período de 1993 a 1996, observando as possíveis mudanças de perfis e a indicação de outros fatos que deverão ser melhor explorados. Nesse período, a existência do SINÁSC vem representando um avanço inquestionável na possibilidade de conhecimento das condiçóes de nascimento e da atenção oferecida às crianças $\mathrm{e}$ às mulheres cariocas.

\section{Metodologia}

Este trabalho refere-se às características dos nascidos vivos e de suas mães, no período de 1993 a 1996, tendo como base 
as mães residentes no município do Rio de Janeiro. $\mathrm{O}$ formulário de $\mathrm{DN}$ é a fonte dos dados para o SINASC, sendo emitido pelos estabelecimentos de saúde, públicos ou privados, cadastrados junto à SMS-RJ. Esses estabelecimentos, após utilizarem os formulários de $\mathrm{DN}$, os enviam, através dos Centros Municipais de Saúde, à Subgerência de Dados Vitais, responsável pelo processamento dos dados. A remessa das DNs pelas unidades de saúde tem periodicidade quinzenal.

As DNs de mães residentes no município do Rio de Janeiro cujos partos foram realizados em outros municípios do Estado do Rio de Janeiro são recolhidas junto à Secretaria Estadual de Saúde (SES). O processamento dos formulários é realizado por uma equipe de dois digitadores alcançando, em média ao ano, 100.000 formulários.

O processamento dos dados é realizado no programa desenvolvido pelo Ministério da Saúde (MS) - DATASUS também denominado SINASC. Esse programa possibilita a entrada dos dados de cada DN, que possui um número de identificação que permite a sua recuperaçáo no sistema. $O$ processamento de cada $\mathrm{DN}$ é atualmente melhor controlado por critérios que definem o dado digitado como pouco provável ou como impossível, impedindo o prosseguimento da digitação. Concluído o processamento das DNs de cada mês de nascimento, é emitido um relatório de crítica, onde incongruências no preenchimento do formulário, erros de digitação ou situações pouco prováveis são conferidos e corrigidos. Esses procedimentos têm sido feitos desde a implantação do sistema.

Nesses quatro anos, algumas mudanças ocorreram no formato e conteúdo das informaçōes que constam do formulário de DN. A diagramação do campo relativo à durafão da gestafão foi modificada, o que provocou um erro sistemático de preenchimento durante o ano de 1995. Também durante aquele ano foram introduzidas duas novas variáveis - pré-natal e aborto.

A tabulação dos dados foi realizada a partir do $\mathrm{TAB}$, um programa de tabulação desenvolvido pelo DATASUS/MS. Esse programa possibilitou a avaliação da distribuição de cada variável constante da $\mathrm{DN}$. Também foi utilizado o programa EPI-INFO - versão 6.0.

Considerou-se que os dados deixados em branco, ou seja, em que não havia o preenchimento do campo correspondente, representavam informaçóes não fornecidas pela unidade de saúde, porém supostamente existentes, e são apresentadas nas tabelas sob a denominação "sem informação". Para as demais variáveis com a opção "ignorado" estabeleceu-se que, quando esse item estava assinalado, o responsável pelo preenchimento do formulário buscou de todas as formas possíveis obter o dado, não logrando, entretanto, sucesso. É sobre o grupo de dados "sem informação" que foram desenvolvidas as análises de qualidade do preenchimento da DN.

A variável filhos tidos, que engloba, na verdade, três variáveis - filhos vionos, filhos mortos $e$ abortos -, apresentou elevada freqüência de não preenchimento (mais de $\mathbf{5 0 \%}$ ). Isso obrigou a avaliação da distribuição dessas variáveis em função de algum outro dado que pudesse indicar um padrão de apresentação desse tipo de informação. A variável que mais possibilitava essa verificação era a idade materna.

Acreditava-se que $o$ nãopreenchimento desse campo na DN representava a ausência de filhos vivos anteriores e/ou de filhos mortos e/ou de abortos, e que a sua ocorrência variaria segundo a idade da mãe. Essa suposição foi baseada na apresentação completamente diferenciada dessas variáveis em relação às demais, levando em conta também que a maior parcela das mães estaria experimentando a primeira gestação $\mathrm{e}$ que a experiência de perda de um filho ou de 
aborto não deveria quantitativamente ser tão freqüente.

A observação da distribuição dessas variáveis - filhos vipos, filhos mortos e abortos segundo a idade da mãe revelou que, para o grupo em que a variável filhos vipos estava em branco, a média de idade era de 22 anos, a mesma média encontrada para o grupo em que esta mesma variável estava preenchida com zero (0). Conforme havia a referência a um, dois, três, quatro filhos, e assim por diante, aumentava a média de idade materna. $O$ mesmo comportamento foi observado para as variáveis filhos mortos e abortos, porém com médias mais elevadas de idade materna. Dessa maneira, considerou-se que o conjunto dos dados apresentados em branco (não preenchidos) representava zero.

Como este relatório refere-se a um período de quatro anos, a apresentação dos resultados se refere, em alguns momentos, à média do período.

\section{Resultados}

Local de Ocorrência e Mès de Nascimento Mais de $90 \%$ das mulheres cariocas têm seus filhos em unidades de sauide da própria cidade

A cobertura dos nascimentos se consolidou, alcançando, em pouco tempo, o patamar dos $100 \%$, náo deixando dúvidas sobre a confiabilidade do sistema. De 1993 a 1996, a média anual de nascidos vivos de mães residentes na cidade do Rio de Janeiro foi de 97.187. O curto período de observação não permitiu fazer qualquer avaliação sobre tendências de crescimento ou decréscimo do número de nascimentos ao ano.

Para o período enfocado, encontra-se a média mensal de 8.099 nascimentos. Entretanto, pode-se observar que em alguns meses do ano - março e maio - essa média é ultrapassada, apresentando aproximadamente $12 \%$ de variação. Fica indicada a existência de concentrações periódicas dos nascimentos, o que futuramente poderá confirmar a presença de "sazonalidade" dos nascimentos (Tabela l).
A maior parte das mães cariocas - em torno de $92,2 \%$ ao ano - teve seus filhos na própria cidade do Rio de Janeiro (Tabela 2). Outras cidades procuradas para realização do parto foram, principalmente, São João de Meriti, São Gonçalo, Niterói, Itaguaí, Nilópolis, Nova Iguaçu e Duque de Caxias. Todas essas cidades juntas responderam, em média, por $7,3 \%$ dos nascimentos. É importante lembrar que essas cidades vêm sendo caracterizadas pela precariedade de recursos na área de saúde, o que faz supor a existência de algum outro fator atrativo, como a realizaçāo indiscriminada de laqueadura tubária por alguns estabelecimentos de saúde.

\section{As Maternidades}

Os servicos de saride puiblicos e pripados conveniados com o SUS concentraram, em 1996, 64,6\% dos recém-nascidos da cidade

$O$ processo de municipalização das unidades de saúde federais inicia-se em 1995 com a pré-municipalização da Maternidade Leila Diniz, localizada no bairro de Jacarepaguá (16 RA - AP 4). Em 1996, três importantes maternidades públicas federars - a Maternidade Praça XV, a Maternidade Carmela Dutra e a Maternidade Alexander Fleming - incorporamse a este processo. Em função disso, a distribuição dos nascidos vivos por tipo de unidade sofre alterações a partir de 1996, pelo aumento da participação da esfera municipal (Tabela 2). Mantém-se a média de participação do setor privado em $33,8 \%$ e da esfera pública em $66,2 \%$. No período enfocado, a participação do setor privado não conveniado com o Sistema Único de Saúde (SUS) passa de $30,3 \%$ para $35,4 \%$. Em relação às unidades privadas conveniadas com o Sistema Único de Saúde (SUS), grande parcela das crianças nasceu na Casa de Saúde Santa Helena, localizada no bairro de Bangu - 17a Região Administrativa (RA) - e na Casa de Saúde e Maternidade de Campinho, localizada no bairro de Marechal Hermes - 15a RA.

A ocorrência de partos domiciliares na cidade, nesses quatro anos, mantém-se discreta, 
oscilando em torno de $0,06 \%$ (Tabela 3).

\section{Sexo \\ Continuam nascendo mais meninos do que meninas}

Predominam os recém-nascidos do sexo masculino (Tabela 3 ). A razão de masculinidade - a relação entre o número de crianças do sexo masculino e feminino - foi, em média, de 1.051 meninos para 1.000 meninas.

A freqüência de não-preenchimento desse dado permaneceu, em média, em $0,4 \%$. Considera-se boa a qualidade do preenchimento dessa variável. Cabe lembrar a inexistência, no formulário da $\mathrm{DN}$, da opção "sexo ignorado", o que dificulta o seu preenchimento naqueles casos de genitália indefinida, como para as situações de malformaçóes congênitas.

\section{Peso ao Nascer \\ $O$ baixo peso ao nascer estapa pinculado à prematuridade em $40 \%$ dos casos, e essas duas situafóes juntas contribuem para a mortalidade perinatal}

O peso ao nascer é uma das principais informaçóes para a avaliação das condições de gestação. $O$ baixo peso, presente em gestações a termo e únicas, indica a presença de intercorrências - desnutrição materna, infecções, transtornos hipertensivos maternos. Estes problemas acabam por afetar o desenvolvimento intra-uterino, colocando em risco a capacidade de sobrevivência desses recém-nascidos. Problemas no acompanhamento pré-natal contribuem para a existência de boa parte desses casos.

A variável peso ao nascer apresentouse, durante o período, com um mesmo perfil de distribuição. A freqüência de baixo peso (abaixo de 2.500 gramas) oscilou pouco, em torno de 9,5\% (Tabela 3). Esse percentual deve ser relativizado em função da duração da gestação, ou seja, da ocorrência de prematuridade, daí a presença do baixo peso e do tipo de gravidez, apesar de ser pouco freqüente, com a presença de gestaçóes múltiplas.

A frequiência de prematuridade, entre os recém-nascidos com baixo peso, oscilou de 40 a $46 \%$ respectivamente para os anos de 1993 e 1996. Excluindo-se os recém-nascidos prematuros dessa avaliação, a freqüência de baixo peso para as gestaçóes a termo cai para a faixa de 5,3 a 5\% respectivamente em 1993 e 1996. Essas avaliações não discriminaram o tipo de gravidez - única, dupla, tríplice, mais de três. Entretanto, levando-se em consideração que a maioria das gestaçóes foi única - aproximadamente $97 \%$ - essa característica não influenciou as distribuiçōes apresentadas.

A maior parte dos nascidos vivos teve o peso adequado, sendo que $60 \%$ situavam-se na faixa de 3.000 a 3.999 gramas. O sobrepeso (igual ou superior a 4.000 gramas) apresentouse em $4,7 \%$ dos bebês.

Em 1993, a ausêthcia de informação sobre o peso ao nascer foi de $1,2 \%$. No ano de 1996 esse percentual caiu para um pouco menos que a metade - $0,5 \%$. Apesar dessa ausência de informação não ser expressiva, ela vem caindo, confirmando a impressão de que o sistema vem se aprimorando.

\section{Apgar no 1- e 5o Minutos}

\section{Melhora a informafão sobre Apgar}

$O$ índice de Apgar representa as condições de vitalidade dos recém-nascidos. É um índice medido, $\mathrm{cm}$ geral, pelo pediatra da sala de parto, no primeiro e no quinto minutos de vida através de alguns sinais - cor da pele, respiração, batimentos cardíacos, tônus muscular e respostas a estímulos nervosos. Esses sinais recebem pontuaçốes de zero a dois que são somadas, configurando um valor final cuja variação é de 0 a 10.

É importante ressaltar que o Apgar igual a zero (0), seja ele do primeiro ou do quinto minuto, não indica natimortalidade, mas condições de extrema gravidade, nas quais, entretanto, não é confirmado o óbito. Dessa forma a apresentação da distribuição do Apgar 
está considerando o registro do Apgar como zero $(0)$ no primeiro ou no quinto minuto.

Outro aspecto a ser considerado em relação ao Apyar igual a zero é que, diante dos avanços dos recursos utilizados em neonatologia, aquelas situaçóes de extrema gravidade no nascimento, atualmente, podem ser revertidas.

O índice de Apgar foi trabalhado em três faixas de valores. Um valor de Apgar menor ou igual a três (3) equivale à anóxia grave; de quatro (4) a seis (6), à anóxia moderada; sete $(7)$ corresponde à anóxia leve e acima de oito (8) equivale aos recém-nascidos em boas condiçôes ${ }^{3 .}$ Como era esperado, a maioria dos nascidos vivos, nesses quatro anos, encontrava-se em boas condiçóes ao nascimento (Tabela 3 ).

De 1993 a 1996, a freqüência de anóxia grave tem se apresentado em torno de $2,3 \%$ para o Apgar no primeiro minuto e $0,5 \%$ para o Apgar no quinto minuto. A anóxia moderada manteve-se em média presente em 9\% dos nascidos vivos para o Apgar no primeiro minuto e em $2,1 \%$ para o quinto minuto. A menor presença de gravidade no quinto minuto reflete a recuperação clínica das condições dos recém-nascidos, após receberem cuidados adequados.

A presença de anóxia moderada, medida através do Apgar do primeiro minuto de vida, apresenta-se com variaçöes expressivas - de 14 a $22 \%$. Essas diferenças foram maiores do que aquelas encontradas para o Apgar no quinto minuto, oscilando entre 3,8 e $4,9 \%$. Possivelmente isso se deve à existência de alguma dificuldade técnica para definição de um nível limítrofe, entre o recém-nascido "normal" e aquele com algum grau de sofrimento, pois alguns dos sinais que compóem o Apgar apresentam certo grau de subjetividade.

Desde a implantação do SINASC, o não-preenchimento do Apgar, principalmente o do quinto minuto, chamava a atenção pela elevada freqüência (Tabela 3 ). Tal fato inviabilizava uma análise segura do perfil dessa variável.

A remessa de relatórios sobre a qualidade do preenchimento da DN aos estabelecimentos de saúde da cidade que mais emitiam DN resultou na melhoria do preenchimento do formulário. Nesses relatórios abordava-se, de maneira particular, o desempenho de cada unidade de saúde e os campos da DN que mais eram deixados em branco, entre eles o Apgar. O nãopreenchimento do campo reservado para o registro do Apgar no primeiro minuto passa de $9,5 \%$ em 1993 para 3,9\% em 1996. Em relaçâo ao Apgar no quinto minuto, a queda de ausência de informaçōes foi ainda maior, ou seja, de 18,5\% em 1994 para 4,4\% em 1996 (Tabela 3).

\section{Duraçāo da Gestaçāo}

A prematuridade contribui para a mortalidade perinatal, expressando, em parte, a manutenfão de problemas na assistência durante o pré-natal

A partir da duração da gestação é possível identificar a presença de prematuridade e problemas no desenvolvimento intra-uterino, ao confrontar a duração da gestação e o peso ao nascer.

Define-se por prematuridade aquelas gestaçóes com duração de até 36 semanas (inclusive). Em relação ao desenvolvimento intra-uterino é possível identificar nas gestações a termo (37- a $41^{\underline{a}}$ semanas), os recém-nascidos considerados pequenos para a idade gestacional (PIG). Consideram-se os bebês cujas gestaçōes tiveram duração igual ou superior a 42 semanas como recém-nascidos pós-termo.

A freqüência de prematuridade esteve, em média, em 6,4\% (Tabela 4). Ao se discriminar a duração da gestação, encontrouse, para os nascidos vivos a termo e pós-termo, a frequiência de $5,7 \%$ de baixo peso em 1993 , de $6,1 \%$ em 1994, de $5,9 \%$ em 1995 e $5,4 \%$ em 1996.

Tanto a prematuridade, quanto a existência do baixo peso ao nascer, para as gestaçóes a termo e pós-termo, indicam que o desenvolvimento intra-uterino foi prejudicado 
por $\operatorname{algum}(s)$ fator(es). Em geral, esses prejuízos referem-se a processos não identificados e não controlados a tempo como infecçốes que afetam o feto, a desnutrição materna, a hipertensão materna ou outras doenças preexistentes ou específicas da gestação. Essas situações deveriam estar sendo reconhecidas através do acompanhamento prénatal e conduzidas adequadamente ${ }^{4}$. A existência de prematuridade e/ou baixo peso representa problemas objetivos à sobrevivência do recém-nascido, determinando muitas vezes a sua viabilidade ou as causas da sua mortalidade.

A ausência de informações sobre a duração da gestação - "sem informação" - vem caindo de 1993 para 1996, o que representa a melhoria do preenchimento do formulário (Tabela 4). O percentual de gestações com tempo de duração ignorado no período ficou, em média, em $0,8 \%$.

Tipo de Gravides

Mantém-se baixa a frequiência de gestafões muiltiplas na cidade

A existência de gestaçóes múltiplas não alcança freqüências importantes na cidade do Rio de Janeiro, girando em torno de $1,9 \%$ ao ano para o período analisado. Entretanto, a presença de uma gravidez múltipla (gêmeos, trigêmeos etc.) configura uma gestação com maior risco, requerendo acompanhamento diferenciado. Em geral, nessas gestaçōes há uma maior frequiência de baixo peso e prematuridade.

A frequiência de não-preenchimento do campo sobre tipo de gravidez na DN - "sem informação" - não era alta desde o início do SINASC e vem caindo nestes quatro anos (Tabela 4). Para os registros ignorados observase, da mesma maneira, percentuais inexpressivos - $0,02 \% \mathrm{em}$ média.

\section{Tipo de Parto}

$E$ Erescente a realizafão de partos cesarianas nas unidades de saúde do setor privado

O crescimento da realização de partos cesáreos tem sido objeto de interesse de vários setores da sociedade. Os órgãos gestores do sistema de saúde, os grupos organizados da sociedade e os profissionais de saúde envolvidos com a prestação de cuidados à saúde da mulher e da criança têm investido no monitoramento dessa tendência e na sua reversão.

As indicações para realização da cesariana existem e foram definidas tecnicamente pelos órgãos especializados e representativos da área de obstetrícia. No entanto, a elevada freqüência desse tipo de parto faz crer que essas indicaçóes não vêm sendo seguidas. Na cidade do Rio de Janeiro, a freqüência de cesarianas passou de $41,2 \% \mathrm{em}$ 1993, para 46,9\% em 1996 (Tabela 4).

Optar pelo parto cesáreo, naquelas situaçōes em que se poderia deixar evoluir o parto espontâneo, pode introduzir fatores que aumentarão as taxas de mortalidade materna $e$ neonatal precoce. Certamente, a conduta obstétrica - corretamente aplicada - para a realização de uma cesariana pode salvar uma vida. A prática abusiva dessa conduta, e na proporçâo atualmente presente, aumentará a frequiência das complicaçôes que poderão resultar desse tipo de procedimento.

A realização de cesariana foi mais freqüente nos estabelecimentos privados e para as mulheres com nível de instruçáo mais alto. A observação do perfil das unidades de saúde da cidade, que será objeto de um relatório específico, possibilitou identificar padrōes quanto à realização de cesarianas. Aquelas unidades, caracterizadas por atenderem principalmente às mulheres com melhores condiçōes sócio-econômicas, apresentaram as maiores freqüências de realização de cesariana, ultrapassando em muito a média desse tipo de parto encontrada para o município. As razóes para esta situação estáo relacionadas a questóes socioeconômicas e culturais, que ditam formas de atuar profissionalmente nem sempre voltadas para a promoção da saúde.

A freqüência de dados sobre o tipo de parto deixados em branco vem caindo, mantendo-se na média de $0,4 \%$. Já o percentual de informação ignorada é extremamente baixo 
- 0,01\%. Esta última situação provavelmente envolve as DNs fornecidas alguns dias após a realização do parto e em que não havia registro no prontuário sobre a intervenção realizada mas confirmava-se o nascimento na unidade de saúde.

\section{Pré-natal \\ A frequiência de realizafão de pré-natal surpreende as expectatipas}

O acompanhamento pré-natal representa uma ação fundamental para qualificação da atenção prestada à saúde da mulher $\mathrm{e}$ da criança. Muitas das causas da mortalidade materna e da mortalidade perinatal estão relacionadas diretamente à não-identificaçāo, durante o prénatal, de condiçóes que poderão afetar a saúde da mulher. Entre essas situações estão as infecções (sífilis, AIDS, rubéola), a hipertensão arterial, o diabetes mellitus, a desnutriçáo etc. Outros processos patológicos originam-se durante a própria gestação, como hipertensão e diabetes gestacionais. Todas estas condições, que poderiam ser perfeitamente controladas, quando não identificadas podem determinar a prematuridade, o baixo peso, dificuldades na condução do trabalho de parto; quadros que definirão situaçóes de risco e que terminam por levar à mortalidade materna e perinatal.

A informação sobre a realização do prénatal foi introduzida na DN em 1995. Por isso, a observaçáo dessa variável ficou restrita a dois anos. Pode-se observar que, mesmo no ano de 1995 , quando a freqüência de não-preenchimento desse campo foi extremamente elevada - $23,7 \%$ - a realização do pré-natal estava indicada em $67,8 \%$ dos nascidos vivos. No ano de 1996 , quando a freqüência de não-preenchimento cai para $6,5 \%$, c percentual de realização de prénatal atinge 76,2\% (Tabela 4).

Segundo o Programa de Assistência Integral à Saúde da Mulher - PAISM - a mulher é considerada assistida no pré-natal quando comparece a um número de seis consultas durante a gravidez. Tendo esse parâmetro como referência, a frequêência de realização de pré-natal na cidade do Rio de Janeiro em 1995 foi de 46,1\% e, em 1996, de 50,1\%. Os dados de 1996 aproximam-se do que foi encontrado em recente pesquisa realizada no Brasil, em que a frequiência de realização do pré-natal com quatro ou mais visitas foi de $77 \%^{5}$. Deve-se observar, entretanto, que os dados apresentados na $\mathrm{DN}$ não permitem a fragmentação da análise sobre a realização de pré-natal em quatro consultas ou mais, o que possivelmente justifica as diferenças encontradas.

A expressiva freqüência de nãopreenchimento do campo da DN sobre a realização de pré-natal, no ano de 1995 , provavelmente deveu-se ao fato dele ter sido introduzido no formulário naquele ano e os responsáveis pelo preenchimento não estarem esclarecidos sobre o seu uso. A freqüência de informaçōes ignoradas sobre pré-natal permaneceu baixa nesses dois anos, em torno de $2,5 \%$.

\section{Idade da Mãe}

Cresce o número de mães adolescentes

A distribuição etária das mães na cidade manteve-se a mesma, com o predomínio dos grupos etários dos 20 aos 29 anos (Tabela 5). A freqüência média de nascidos vivos de mães adolescentes foi de $17,4 \%$. A frequiência de mães adolescentes idade menor ou igual a 19 anos - vem indicando uma tendência de crescimento que só poderá ser confirmada com maior tempo de observação. Essa freqüuência apresentou uma variação de 27,9\%, de 1993 a 1996. Entretanto, no mesmo período, o grupo de mães de dez aos 14 anos de idade foi o que apresentou proporcionalmente a maior variação, ou seja, $73,9 \%$.

A gravidez na adolescência compreende uma série de condiçóes anatômicas, fisiológicas, psicológicas, sociais e culturais - que poderão determinar um maior risco para a mortalidade perinatal e para a mortalidade materna. Dessa forma, é um grupo que requer acompanhamento específico durante o pré-natal e orientaçóes sobre os métodos anticoncepcionais disponíveis e a sua 
correta forma de utilização.

A freqüiência de não-preenchimento da idade da mãe, na DN, vem caindo (Tabela 5), tendo ficado em média, no período, em $2,6 \%$.

\section{Escolaridade da Mãe}

Melhora o nível de instrufãa das mães

A escolaridade da mãe é outra importante variável para a análise das condiçóes de risco para mortalidade infantil e materna. Ela expressa a situaçáo socioeconômica da mãe e do contexto familiar em que estará inserido o recém-nascido. Vários trabalhos desenvolvidos na área da saúde da criança comprovam a importância do grau de instruçâo dos pais e, em particular, da mãe para o risco daquela adoecer e morrer durante a infância.

$O$ acesso às açóes preventivas imunização, terapia de reidratação oral, acompanhamento pré-natal, aleitamento materno etc. - e o seu correto entendimento e utilização pela população em geral são profundamente influenciados pelos anos de estudo de cada pessoa. $\mathrm{O}$ nível de instrução interfere na capacidade de encaminhamento de soluções e nos tipos de opçóes que cada um define.

$\mathrm{Na}$ cidade do Rio de Janeiro, o perfil de escolaridade das máes mantém-se inalterado de 1993 a 1996 (Tabela 5). No entanto, observa-se um relativo decréscimo das mães com nenhuma escolaridade ou $1^{\circ}$ grau incompleto $e o$ aumento da freqüência de mães com escolaridade do 1 o grau completo $e$, de forma mais evidente, para o $2^{\mathrm{O}}$ grau. Com escolaridade do nível superior, encontravamse em média $10 \%$ das mães.

A qualidade do preenchimento do campo sobre escolaridade mostra melhorias. Entretanto, o percentual de informação ignorada para escolaridade vem aumentando (Tabela 5), possivelmente pelo não-registro desse dado nos formulários hospitalares $\mathrm{e}$ prontuários médicos.

Filhos Vivos, Filhos Mortos e Abortos Aproximadamente $50 \%$ das criancas nascidas a cada ano representavam a primeira experiência

\section{de maternidade das mulberes}

O conjunto das variáveis - filhos vivos, filhos mortos e abortos - serve para caracterização da história gestacional anterior ao recém-nascido para o qual está sendo emitida a DN. Esse histórico permite a identificação da multiparidade, da natimortalidade e da freqüência de abortos. Todas essas ocorrências poderáo configurar uma situação de risco para a sobrevivência infantil e, dessa forma, indicar cuidados de saúde diferenciados no primeiro ano de vida.

Após a avaliação da qualidade dessas informaçôes, considerando até 1995 os campos deixados em branco como sendo "sem informaçāo", reconsiderou-se essa análise. Tal procedimento foi explicado no item sobre a metodologia e, em resumo, assumiu os registros deixados em branco como zero (0). Em função deste recorte metodológico, para essas variáveis não haverá frequiência de informações ignoradas.

Aproximadamente $50 \%$ das crianças nascidas a cada ano representavam a primeira experiência de maternidade daquelas mulheres (Tabela 5). A diminuição da fecundidade possivelmente tem afetado o comportamento dessa variável. A freqüência média de mulheres que havia tido um (1) filho esteve, nos quatro anos de observação, em 28,5\%. A distribuição encontrada assemelha-se àquela apresentada para Porto Alegre, no período de 1992 a 19956,7.

A experiência de filhos mortos apresentou-se, em média, de 1993 a 1996, em 4,6\%. Essa freqüência, que em 1993 era de 6\%, em 1996 chega a 3;1\% (Tabela 5). Esse decréscimo pode estar relacionado com a diminuição da mortalidade infantil, principalmente às custas das causas pósneonatais, e com a diminuição da fecundidade.

A ocorrência de aborto começou a ser medida a partir de 1995, ano em que essa variável foi introduzida no formulário da $\mathrm{DN}$. A freqüência observada de aborto situou-se em $14,2 \%$ para 1995 e $15,6 \%$ em 1996 (Tabela 5). Não há possibilidade de diferenciar os 
abortos provocados dos espontâneos. A referência da experiência de abortamento nem sempre é feita tranqüilamente pelas mulheres, principalmente quando esses abortos foram provocados. Acredita-se que as freqüências apresentadas sejam parcialmente reveladoras da realidade.

A identificação dos abortos por doenças prévias ou por doenças adquiridas durante a gestação pode permitir a definição de situaçóes de risco em gestaçóes futuras e o correto encaminhamento dos cuidados necessários durante o pré-natal. Da mesma forma, a identificação da multiparidade e da freqüência de mortes infantis. Portanto, esse é um dado que poderá influenciar decisivamente na saúde da mulher, apontando para o planejamento de açóes de saúde específicas e eficazes.

\section{Área de Residência da Mãe e Área de} Ocorrência do Nascimento

Algumas áreas da cidade funcionam como pólos de atraf̧ão das gestantes no momento do parto

A busca por assistência médica no momento do parto segue a lógica da distribuição dos serviços de saúde pela cidade, da oferta de serviços especializados e da identificação informal, pela população, de serviços de qualidade. Essas diferentes lógicas resultam em um movimento entre as áreas que compóem o município, concentrando em algumas delas um maior número de mulheres no momento do parto.

Para a cidade do Rio de Janeiro, a visualização da migraçáo das gestantes no momento do parto foi realizada confrontandose a Área Programática (AP) de residência com a de ocorrência do parto. $O$ município se divide em cinco áreas, sendo que a Secretaria Municipal de Saúde subdivide três delas em outras cinco áreas, totalizando dez (10) APs.

Foram observados, nesses quatro anos, padrōes semelhantes de deslocamento entre as APs, mas com algumas mudanças, principalmente de 1994 para 1996. Destacase a participação da AP 1 , que compreende os bairros do centro, absorvendo percentuais expressivos de mulheres residentes em outras APs, em particular da AP 3.1, que é composta por alguns bairros da zona norte. Provavelmente este fluxo se dê pela localização na AP 1 da Maternidade Praça XV - unidade de referência para gestaçóes de risco - e da Associação Pró-Matre, dois estabelecimentos de saúde concentradores de grande número de partos.

Pode-se observar, de 1993 para 1996, um decréscimo progressivo do deslocamento de gestantes residentes na AP 4 para a AP 1 . Dois aspectos são importantes nessa variação: a abertura de leitos da Maternidade Leila Diniz no segundo semestre de 1994 e o intenso crescimento demográfico da AP 4. Dessa forma, a abertura de leitos desafoga a migração para a AP 1 mas, mantido o ritmo de crescimento da área, as necessidades poderão ampliar-se gradativamente.

No período de março a setembro do ano de 1996, a maternidade do Hospital Municipal Miguel Couto (HMMC) esteve fechada para obras, sendo esse serviço transferido para a Maternidade da Praça XV, o que explica o deslocamento das gestantes da AP 2.1 para a AP 1.

Outras áreas da cidade apresentaramse como importantes receptoras de gestantes no momento do parto, destacando-se a AP 2.1, que envolve os bairros da zona sul da cidade, absorvendo principalmente as mães residentes nas APs 2.2 e 4 . Essa migração está, possivelmente, relacionada à situação sócioeconômica das gestantes c à busca por estabelecimentos de saúde, em geral, privados, que atendem primordialmente grupos sociais específicos.

A AP 3.3 apresentou-se como outra área com importante participação na absorção de boa parte das gestantes residentes na AP 4 e AP 5.1. Deve-se ressaltar a presença, nesta área, da Maternidade Alexander Fleming, que funciona como unidade de referência para gestaçoóes de risco, e da Maternidade de Campinho, uma unidade privada conveniada 
com o SUS.

A AP 4 mostra a crescente ampliação da sua capacidade de absorver as gestantes residentes naquela própria área, a partir da abertura da Maternidade Leila Diniz, aumentando em $75,5 \%$ a absorção das gestantes residentes na área, no período enfocado.

$\mathrm{Na}$ zona oeste, que é composta pelas APs 5 - 5.1; 5.2;5.3 - o fluxo se dá principalmente dentro destas três áreas, destacando-se como grande receptora a AP 5.1, onde se localiza a Casa de Saúde Santa Helena, outra unidade de saúde privada e conveniada com o SUS.

A freqüência de informaçōes ignoradas, não permitindo a identificação da área de residência da mãe no município do Rio de Janeiro, foi pequena para os quatro anos analisados, não ultrapassando $0,8 \%$ dos registros.

\section{Comentários}

Desde o início do funcionamento do SINASC, o sistema vem se aprimorando e adquirindo cada vez mais qualidade. Consolidase, portanto, uma base de dados útil para o monitoramento das condiçōes de nascimento na cidade e das práticas na área da saúde da criança e da mulher.

As distorções da prática médica evidenciam a crescente realização de intervençōes, provavelmente desnecessárias, como indica a elevada frequiência de cesarianas. Os critérios científicos que balizavam as indicaçóes desse tipo de procedimento cedem lugar a orientaçóes de outra natureza, provavelmente ditadas por razóes sócioeconômicas e culturais. Cria-se, dessa forma, uma série de situaçóes de risco, que poderão contribuir para a mortalidade materna $e$ perinatal.

Fica evidente, pelo perfil encontrado nesses quatro anos de SINASC, que a realização de cesarianas está relacionada ao grau de instrução da mãe, indicando, portanto, um viés na conduta médica. De acordo com a inserção social da mulher, indica-se a realização desse tipo de procedimento. É necessário ativar a consciência dos profissionais da área de saúde para informar àquelas mulheres que os procuram sobre porque optar por um procedimento e náo outro, as indicaçóes e os riscos aos quais estaráo expostas.

Com o SINASC abre-se a possibilidade de identificação dos recém-nascidos com baixo peso, dos prematuros, dos recémnascidos de mães adolescentes, enfim, de situaçốes que caracterizam risco à sobrevivência infantil. A partir desse sistema de informações, passa a ser possível diferenciar as necessidades de acompanhamento, nos serviços de puéricultura, para os recém-nascidos com algum grau de risco para sua sobrevivência.

A própria maternidade, uma vez tendo sido estabelecidos os critérios de risco, pode sistematizar os seus trabalhos através do formulário da $\mathrm{DN}$, que servirá como um instrumento de consolidação das informaçóes básicas para discriminação daqueles critérios. Esta experiência de trabalho foi desenvolvida na Maternidade Carmela Dutra, através de convênio com o Núcleo de Estudos de Saúde Comunitária (NESC) da UFRJ, durante a segunda metade do ano de 1995 e início do ano de 1996. Através desse trabalho, os recémnascidos identificados como sendo de risco eram encaminhados, com consulta agendada, aos serviços de puericultura da rede básica de saúde, que então estabelecia um calendário específico de consultas, de acordo com os problemas apresentados. Iniciativas como esta devem ser estimuladas pois poderão incidir em uma reduçáo ainda maior da mortalidade pósneonatal ${ }^{8}$.

As principais causas de mortalidade perinatal e materna estão relacionadas às falhas no atendimento oferecido à gestante. Nesse sentido, as necessidades de investimento se voltam para a qualificação da atenção pré-natal e obstétrica oferecida às mulheres, para a racionalização da oferta dos leitos obstétricos existentes e sua ampliação. Mudanças que 
certamente reduziriam as taxas de mortalidade infantil, perinatal e materna.

Outro aspecto importante revelado pelo SINASC é o deslocamento das gestantes no momento do parto pelas diferentes áreas da cidade. Esse movimento expressa algumas características da organização do sistema de saúde na cidade, como a diferenciação da oferta de serviços de saúde nas áreas que compóem o município e a capacidade, também diferenciada desses serviços, de absorverem essa demanda específica. Outra característica importante é a existência de unidades de saúde identificadas formalmente como sendo de referência pelo próprio sistema de saúde, ou identificadas informalmente como sendo de referência pela qualidade da atenção que prestam à saúde da população.

A qualificação do SINASC vem se dando satisfatoriamente desde a sua implantação, considerando que o percentual de não-registro de informaçóes por variável vem caindo a partir de 1993. Apesar da implantação recente, o SINASC apresenta-se como um sistema de informações de boa qualidade. Em parte, a própria finalidade do documento, ou seja, registrar um nascimento, pode estar influenciando em um maior cuidado no preenchimento da DN. Como reverso dessa situação encontra-se a baixa qualidade do preenchimento da Declaração de Óbito, um documento preenchido exclusivamente por médicos. Provavelmente essas duas situações opostas - nascimento e morte - influenciam no momento do preenchimento dos formulários, o que se refletirá na qualidade dos dados daí extraídos.

Apesar dos avanços, a manutenção de dados ignorados para algumas informações $\mathrm{da}$ DN é uma situação inadmissível. Os responsáveis pelo preenchimento devem ser estimulados a buscar nos registros médicohospitalares ou através de entrevista com a própria gestante ou familiares, as informações que faltam. Portanto, ainda há o que melhorar para consolidar ainda mais este sistema de informaçóes.
É necessário continuar investindo na divulgação das informaçōes produzidas pelo SINASC. A sua utilização pela sociedade e o seu aperfeiçoamento como sistema de informação dependem da disseminação desses conhecimentos.

\section{Bibliografia}

1. CBCD - Centro da OMS para a Classificação de Doenças em Português (MS/USP/OPASOMS) - Núcleo de Estudos em População e Saúde - NEPS/USP. O Sistema de Informação sobre Nascidos Vivos SINASC, Série Divulgação No 7 . São Paulo, 1992.

2. Mello Jorge, M.H.P. de; Gotlieb, S.L.D.; Oliveira, H. de. O Sistema de Informação sobre Nascidos Vivos: Primeira Avaliaçáo dos Dados Brasileiros. Informe Epidemiológico do SUS - Ano V - no 2 Abr a Jun/1996.

3. Fundação Oswaldo Cruz, Escola Nacional de Saúde Pública, Centro de Informação Científica e Tecnológica. Convênio IPLANFIOCRUZ. Projeto "Relação Saúde e Qualidade Ambiental...”. Etapa 6:Produto 3, Relatório Final., maio 1995 (mimeo).

4. Rodrigues, C.S.; Miranda, H.; Júnior, M.; Evangelista, P.A.; Ladeira, R.M. \& Laudares, $S$. Perfil dos nascidos vivos no Município de Belo Horizonte, 1992-1994. Cadernos de Saúde Pública. 13(1):53-57, jan-mar, 1997.

5. BEMFAM - Sociedade Civil Bem-Estar Familiar no Brasil \& Programa de Pesquisa de Demografia e Saúde(DHS) Macro International Inc. Pesquisa Nacional sobre Demografia e Saúde - PNDS, 1996.

6. Secretaria Municipal de Saúde de Porto Alegre, Centro de Vigilância em Saúde, Equipe de Informação em Saúde. PRÁSABER: informaçōes de interesse à saúde, v 1. n 2 (jun). CEDIS, Porto Alegre, RS, 1996.

7. Secretaria Municipal de Saúde de Porto Alegre, Centro de Vigilância em Saúde, 
Equipe de Informação em Saúde. PRÁSABER: informaçóes de interesse à saúde, v l. n 4 (nov). CEDIS, Porto Alegre, RS, 1996.
8. Fundação SEADE. Nascer Aqui. Análise de uma nova fonte de dados sobre os nascimentos. Informe Demográfico $\mathrm{N}^{\circ} 29$. São Paulo, 1995

Tabela 1 - Nascidos Vivos de mães residentes no Município do Rio de Janeiro segundo mês de nascimento, no período de 1993 a 1996.

\begin{tabular}{|c|c|c|c|c|c|c|c|c|}
\hline \multirow{3}{*}{ M ê s } & \multicolumn{8}{|c|}{ A no } \\
\hline & \multicolumn{2}{|c|}{1993} & \multicolumn{2}{|c|}{1994} & \multicolumn{2}{|c|}{1995} & \multicolumn{2}{|c|}{1996} \\
\hline & $n^{0}$ & $\%$ & $n^{0}$ & $\%$ & $n^{0}$ & $\%$ & $n^{0}$ & $\%$ \\
\hline Janeiro & 7.731 & 8,21 & 7.959 & 8,12 & 8.449 & 8,7 & 8.797 & 8,85 \\
\hline F evereiro & 6.991 & 7,42 & 7.959 & 8,12 & 7.663 & 7,89 & 8.394 & 8,45 \\
\hline $\mathrm{M}$ a rço & 7.856 & 8,34 & 9.548 & 9,74 & 9.084 & 9,35 & 9.147 & 9,20 \\
\hline A b ril & 7.672 & 8,15 & 8.938 & 9,11 & 8.521 & 8,77 & 8.438 & 8,49 \\
\hline$M$ a io & 8.681 & 9,22 & 9.168 & 9,35 & 9.097 & 9,36 & 8.778 & 8,83 \\
\hline Junho & 8.083 & 8,58 & 8.359 & 8,52 & 8.853 & 9,11 & 8.358 & 8,41 \\
\hline Ju Iho & 8.412 & 8,93 & 7.984 & 8,14 & 8.466 & 8,71 & 8.606 & 8,66 \\
\hline A gos to & 8.086 & 8,59 & 7.804 & 7,96 & 7.917 & 8,15 & 8.164 & 8,21 \\
\hline Sete $\mathrm{m}$ bro & 8.083 & 8,58 & 7.973 & 8,13 & 7.466 & 7,68 & 8.277 & 8,33 \\
\hline O utubro & 7.897 & 8,39 & 7.689 & 7,84 & 7.238 & 7,45 & 7.516 & 7,56 \\
\hline Novem bro & 7.324 & 7,78 & 6.828 & 6,96 & 6.967 & 7,17 & 6.985 & 7,03 \\
\hline Dezem bro & 7.351 & 7,81 & 7.867 & 8,02 & 7.436 & 7,65 & 7.933 & 7,98 \\
\hline Total & 94.167 & 100,0 & 98.076 & 100,0 & 97.157 & 100,0 & 99.393 & 100,0 \\
\hline
\end{tabular}

Fonte: GIE/COE/SSC/SMS-RJ

Tabela 2 - Nascidos Vivos de mães residentes no Município do Rio de Janeiro segundo tipo de estabelecimento de saúde e município de ocorrência do parto, no período de 1993 a 1996.

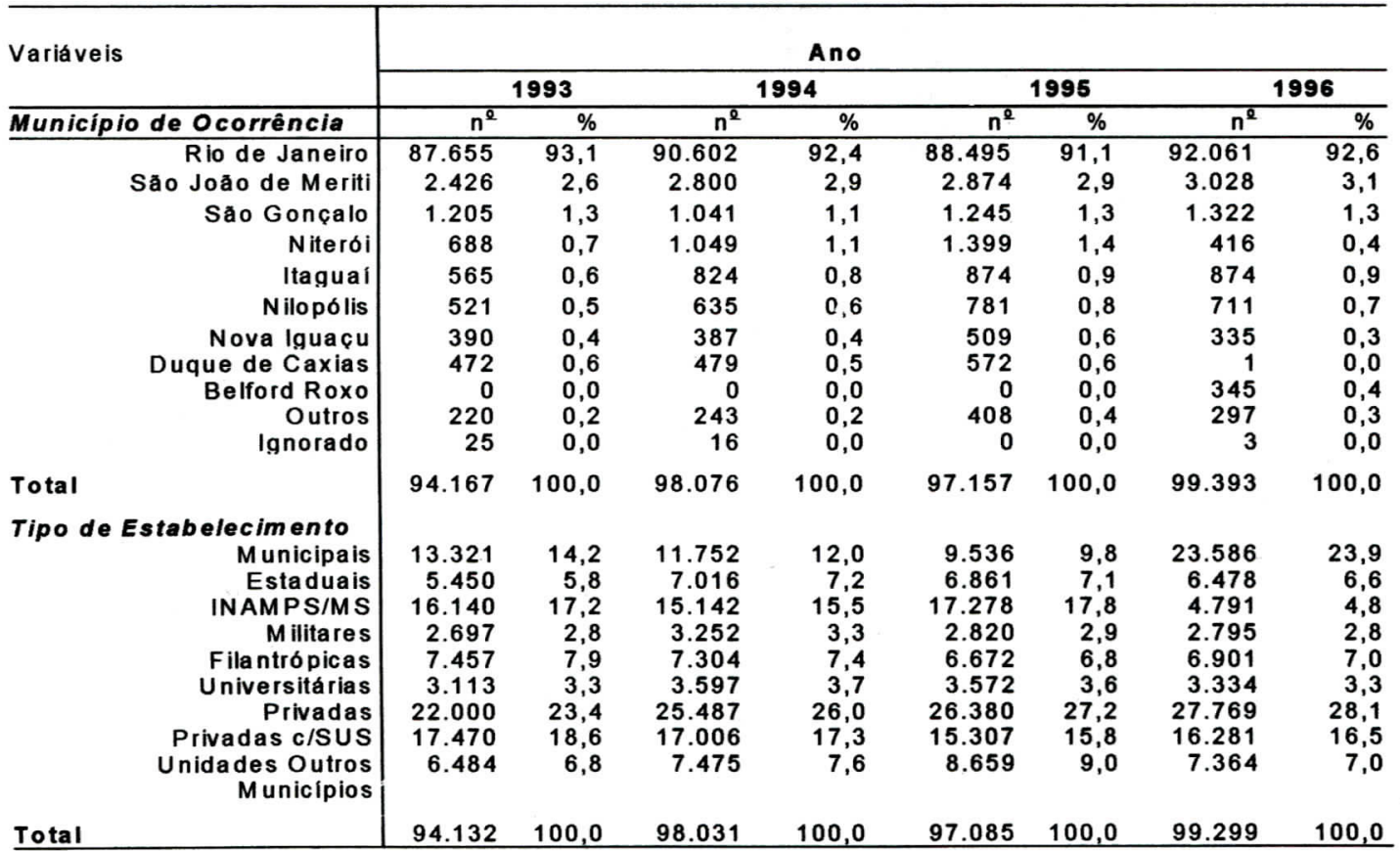

\section{Fonte: GIE/COESSCISMS-RJ}

Obs: no item relativo ao municipio de ocorrência foram excluidos os partos domiciliares.

(*) Para o ano de 1995 foram incluídos no item das unidades municipais os recém-nascidos da Maternidade Leila Diniz.

(") Para 0 ano de 1996 foram incluídos no item das unidades municipais os recém-nascidos das Maternidades da Praça XV, Alexander Fleming, Carmela Dutra e Leila Diniz.

IESUS, VI(2), Abr/Jun, 1997. 
Tabela 3 - Nascidos Vivos de mães residentes no Município do Rio de Janeiro segundo características do recém-nascido, no período de 1993 a 1996.

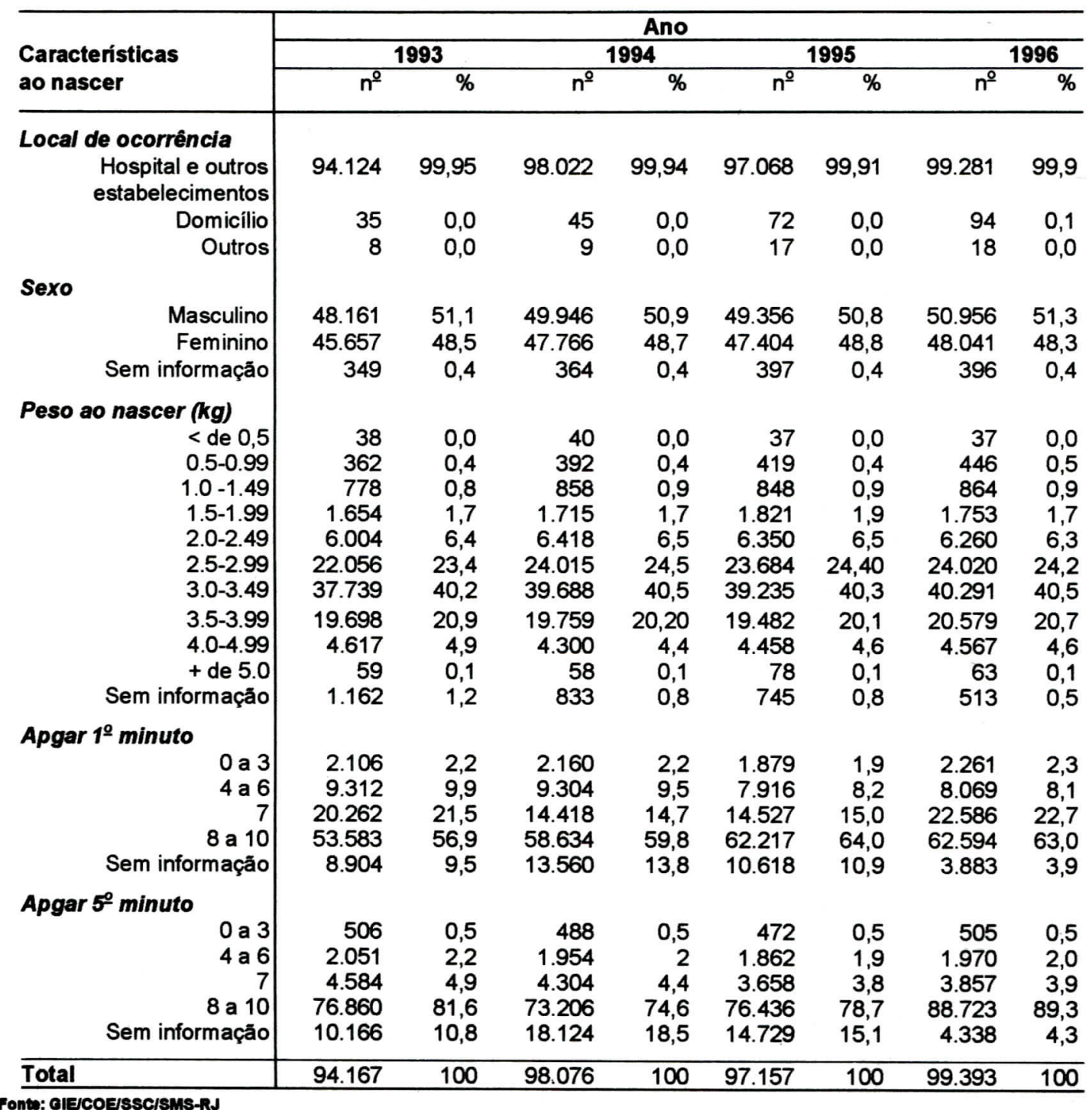


Tabela 4 - Nascidos Vivos de mães residentes no Município do Rio de Janeiro segundo características da gestação, no período de 1993 a 1996.

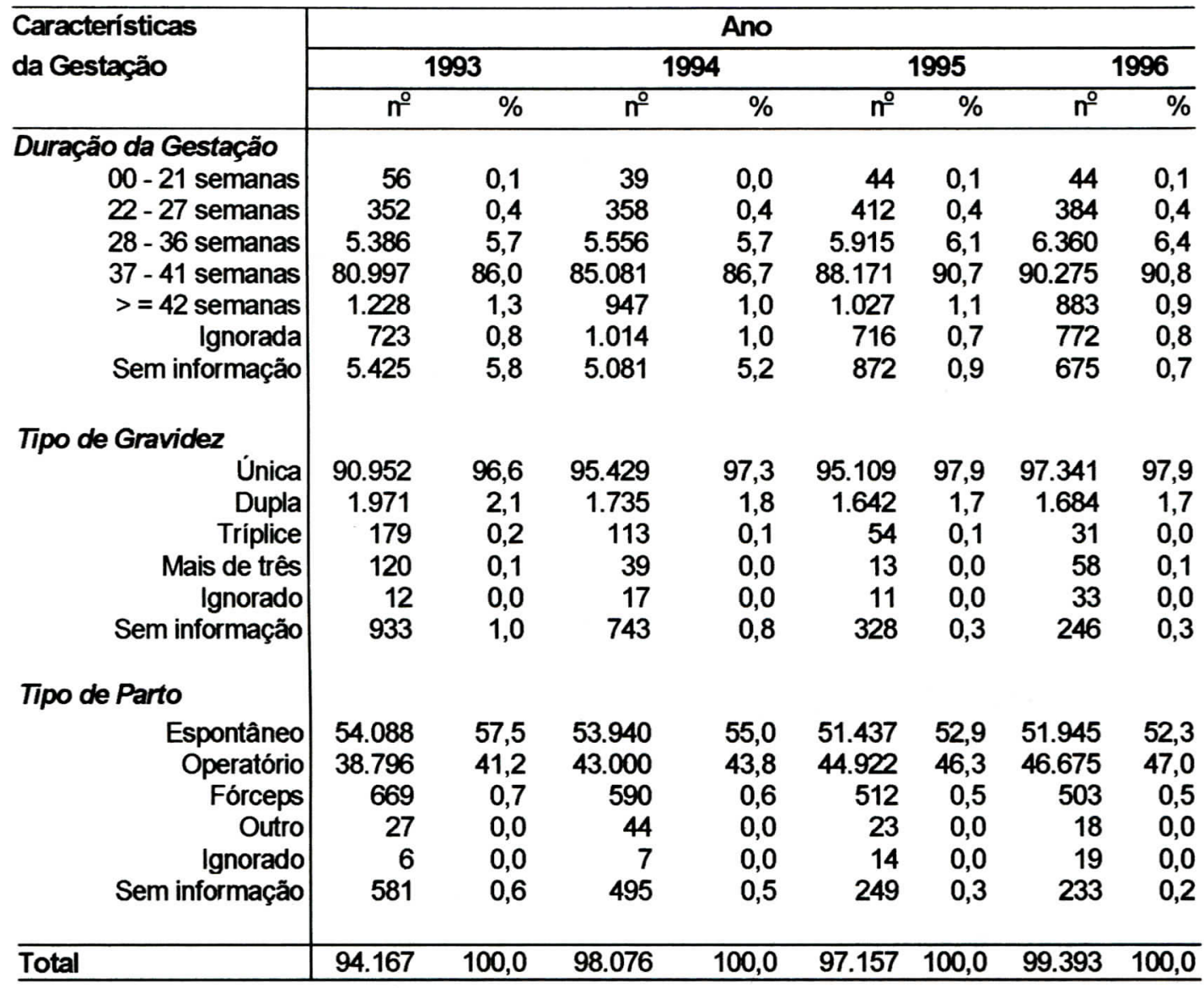

Fontw: GIE/COEISSC/SMS-RJ 
Tabela 5 - Nascidos Vivos do Município do Rio de Janeiro segundo características maternas, no período de 1993 a 1996.

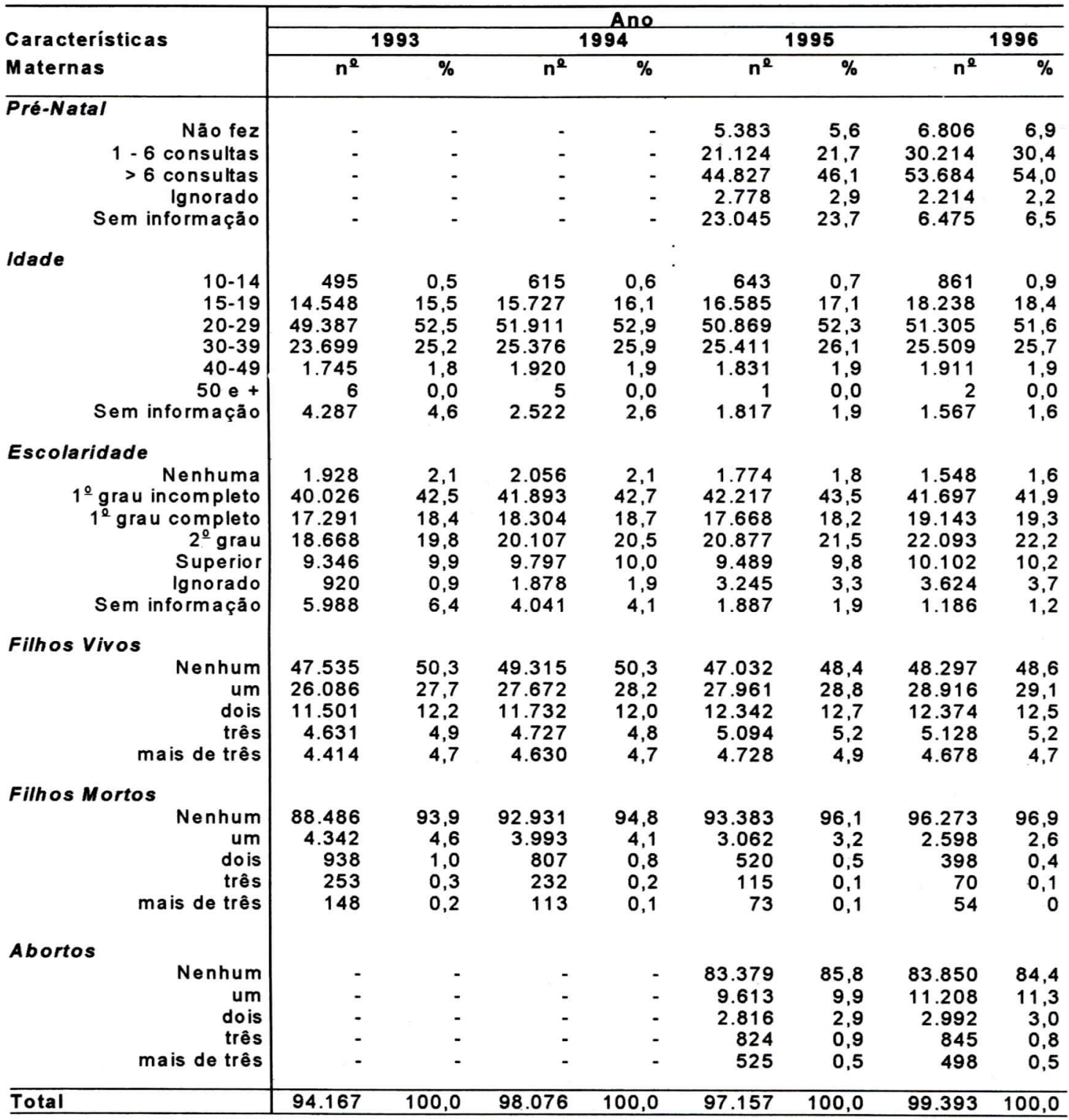

Fonte: OIEJCOEISSCISMS-RJ 